In Chapter Five, on the Case Study approach, they make the important point that although it may not be possible to generalize from case studies, it may be possible to reject existing generalizations. Unfortunately in these discussions they cling too faithfully to the concept of a 'random' sample. This continues to be evident in the section on sampling frames ( $p p$ 72-78), the problems of which make one wonder why statisticians believe it possible to generalise from any survey technique.

The Chapter on Questionnaires is excellent, and to devote a whole Chapter to 'The (Survey) Team' also shows the practical outlook of the authors. They devote chapters to Data Preparation and Processing and to Presentation and Release of the Data. The book finishes with three chapters on types of surveys: Households and Household Members, Agricultural Holdings, and Monitoring, Evaluation, Surveillance, and Forecasting.

For someone, especially an academic, embarking on a sample survey, and wishing to graft practical considerations onto what they have been told in statistics classes, this book is invaluable. However, for the reasons discussed above the authors have given their book an over-ambitious title.

\section{References}

Carruthers, I., 1979, 'Breadth, depth or replications?--sampling problems with insufficient time, money or background', paper given at RRA Conference, IDS, Sussex

Chambers, R., 1980, 'Rapid rural appraisal: Rationale and Repertoire', Discussion Paper 155, IDS, Sussex

Ellman, A., 1979, 'Cost Effectiveness of Rapid Appraisal for Rural Project Preparation', paper given at RRA Conference, IDS, Sussex

Fallon, P., 1979, 'Comments on Mick Moore's "Denounce the Gang of Statisticians etc", paper given at RRA Conference, IDS, Sussex

Moore, M., 1979, 'Denounce the Gang of Statisticians. Struggle Against the Sample Line. Unite the Researching Masses against Professional Hegemony', paper given at RRA Conference, IDS, Sussex

\title{
Deborah Barndt 1980 Education and Social Change: a Photographic Study of Peru
}

\section{Kendall/Hunt Publishing Co, Iowa, $\$ 19.95$}

\section{Kate Young}

This is a published version of a doctoral thesis which sets out to explore the dynamics of the conscientisation process. The author explains in the introduction that she had been influenced by Freire's theory and method of conscientisation - 'the development of a critical consciousness achieved through dialogical (sic) educational programmes concerned with social and political responsibilities" - and had determined to see how this method was being applied in the Peruvian context. The Peru to which she went was itself in a period of considerable social change: the revolutionary military government of Velasco which had taken power in 1968 had introduced a number of reforms including agrarian and educational reform, the expropriation of a number of foreign companies, the redirection of national capital to the industrial sector, with the aim of achieving 'a pluralistic and humanistic society, neither capitalist nor communist, based on the social democracy of full participation'. By 1976 when Ms Barndt arrived in Peru the contradictions and difficulties in this so-called third way had become evident. The

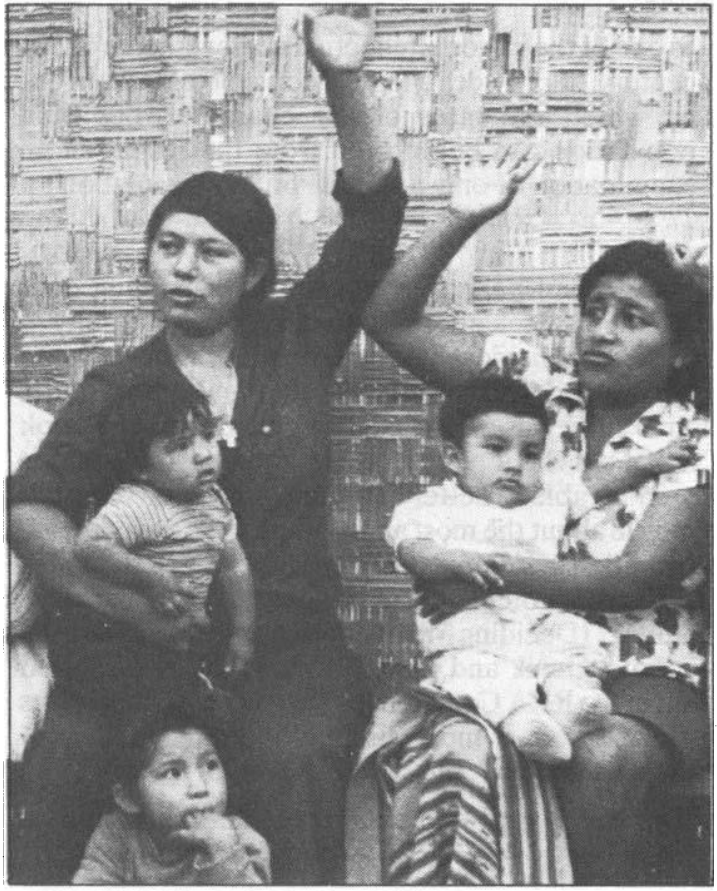


ousting of Velasco from the Presidency the year before was accompanied by a shift away from the more 'socialist' experiments (such as the establishment of a social property sector), toward reinforcement of economic growth based on foreign and private rather than state investment -in part a result of the pressure brought to bear on the government to repay the enormous foreign debt left by the Belaunde Govern* ment. The new president Morales Burmudez introduced an austerity package (including a massive increase in the price of basic foodstuffs, holding down salary increases), and gave support to the private sector at the expense of the social property sector. At the same time the press was more tightly controlled than before, and all opposition magazines were closed because they 'led campaigns to obstruct the fulfillment of measures to reactivate the economy, to destroy the unity of the armed forces, and to subvert order and public tranquility'.

It was in this context that Ms Barndt started studying the on-going literacy programmes. These were basically two: ALFIN - the national literacy programme of the government and ALFALIT, that of the evangelical churches (largely sponsored by North American protestant groups and mainly concerned with religious education and distribution of US/AID foodstuffs through nutrition programmes). In her review of these programmes she points to the contradictions between the intentions of the government, national literacy campaign planners, local teachers and the needs of the differing groups being serviced; at the same time she points to the political tensions within which they worked. ALFALIT in particular was plagued by a decline in financial support given the US disapproval of the Velasco regime, the strongly anti-communist direction of ALFALIT (the founders and current director of it being exiled (ubans), and the Peruvian Government's insistence that ALFALIT adapt its programme to the government's, and lastly, differing demands of local people. ALFIN itself changed its focus at least three times during the period of the military government; in part this derived from the tension between regional and national aims, actual ability to implement the programme, and after 1975 the increasing conservatism of the government. In 1977 in fact ALFIN was abandoned.

The last part of the book deals with her own adaptation of the conscientisation method - the photo-novel-in communities around Lima largely composed of migrants. Her novel contrasts two ways of teaching: the ALFIN conscientisation method, and the traditional limited and hierarchial method. After discussing how she came to develop it and the problem in such teaching to move from the individual and descriptive level to the structural and determination to change, she gives a brief account of four women's discussions of the novel. These four women all live in a community on the outskirts of Lima with many of the problems common to all Pueblos Jovenes-lack of security of tenure, lack of services, lack of employment. Although the whole thesis in a sense builds up to these interviews they are surprisingly 'thin' and the interpretations given seem to make very little use of the wider context which the author has analysed. This is in part because of the methodology which she criticises in the last section and in which she makes a comparative critique of Freire, Martin, Smith and herself. This section itself lacks bite and appears rather inconclusive.

The book is full of photographs, and indeed the subtitle of the book is A Photographic Study of Peru (which is a little misleading). Many of them beautifully illustrate the text, but one longs for better quality printing which would have made many of them more intelligible. At the same time one grievous omission is some comparative photographs to show how the other half (or is it merely $20 \%$ ) live. 